\title{
Daylight Photodynamic Therapy Versus 5-Fluorouracil for the Treatment of Actinic Keratosis: A Case Series
}

\author{
Gaston Nestor Galimberti (D)
}

Received: November 23, 2017 / Published online: January 10, 2018

(c) The Author(s) 2018. This article is an open access publication

\begin{abstract}
Introduction: The incidence of actinic keratosis (AK) continues to increase worldwide. Currently available options for the treatment of $\mathrm{AK}$ include topical 5-fluorouracil (5-FU) and daylight-mediated photodynamic therapy (DLPDT). This split-face pilot study compared DLPDT using 16\% methyl aminolevulinate (MAL) cream versus 5 -FU cream in patients with $\mathrm{AK}$ on the face/scalp.
\end{abstract}

Methods: Five male subjects (mean age 70 years) with grade I-III AK on the face/scalp were enrolled. Subjects received a single session of DL-PDT with $16 \%$ MAL on one side and topical 5\% 5-FU for 21 days on the other side. Evaluations of efficacy, safety, and subject satisfaction were conducted $48 \mathrm{~h}, 7$ days, 14 days, 1 month, and 3 months after treatment.

Results: At 3 months, the lesion complete response rate was $80 \%$ and $93 \%$ for DL-PDT and 5 -FU, respectively. Lesion partial response was $20 \%$ and $7 \%$, respectively. Fewer treatment-related adverse events (AEs) were reported with

Enhanced content To view enhanced content for this article go to http://www.medengine.com/Redeem/ B90DF06076A5F2FA.

G. N. Galimberti ( $₫)$

Department of Dermatology, School of Medicine,

Hospital Italiano de Buenos Aires, Buenos Aires,

Argentina

e-mail: gaston.galimberti@gmail.com
DL-PDT than with 5-FU, and they resolved spontaneously in 5-7 and 27-30 days, respectively. Subjects preferred DL-PDT because of the lower incidence of AEs and rapid recovery compared with 5-FU.

Conclusion: DL-PDT is a convenient alternative to 5-FU with good efficacy and a favorable safety profile, allowing patients to effectively treat their AK without compromising their social life. Funding: Galderma.

Keywords: 5-Fluorouracil; Cancerization field; Daylight-mediated photodynamic therapy; Methyl aminolevulinate; Photodamage

\section{INTRODUCTION}

Actinic keratoses (AKs) are precancerous lesions with an increasing incidence worldwide [1]. Currently, there are various options available for the treatment of AK including topical and photodynamic therapy (PDT). Topical 5-fluorouracil (5-FU) has been shown to be efficacious in treating AK [2]. Moreover, daylight-mediated PDT (DL-PDT) has offered a simpler, safer, and more convenient-as well as equally efficacious-option compared with conventional PDT [3-6].

The objective of this comparative pilot study was to evaluate the efficacy, safety, and patient satisfaction of DL-PDT using 16\% methyl aminolevulinate (MAL) cream versus topical 
treatment using 5-FU cream in patients with $\mathrm{AK}$ on the face and scalp.

\section{METHODS}

The study included five subjects with grade I-III $\mathrm{AK}$, according to Olsen's classification [7], on the face or scalp. The subjects were randomly recruited through the daily consultation of the cutaneous oncology agenda of the Department of Dermatology at the Hospital Italiano de Buenos Aires in November 2016.

All subjects were male with a mean age of 70 years (range 60-80 years). They presented with phototype I (3 subjects; 60\%) and II (2 subjects; $40 \%$ ). All subjects provided written informed consent prior to participation in the study.

The study followed a split-face design. The region of interest on the face or scalp was divided into two areas, each receiving a single session of DL-PDT or topical 5\% 5-FU treatment.

Prior to DL-PDT, the treatment area was cleansed with $0.9 \%$ saline solution. Organic SPF 30 sunscreen was applied to the treatment area as well as all areas of the face/scalp exposed to sunlight. Subsequently, surface curettage was performed to remove lesion crusts and scales. A thin layer of $16 \%$ MAL cream was applied ( $1 \mathrm{~g}$ per area), and the subjects left the clinic with instructions to initiate direct exposure to sunlight within 30 min of MAL cream application. Moreover, they were instructed to allow $2 \mathrm{~h}$ of exposure for optimal treatment results, as previously recommended $[1,8]$. At the end of the 2-h exposure, subjects removed the residual MAL cream using wet towels and applied sunscreen for continued protection.

For the opposite treatment area, subjects were instructed to apply 5-FU cream at home for a period of 21 days. Following cleansing of the treatment area with soap and water, 5-FU cream was applied homogeneously on the lesion and surrounding area $1 \mathrm{~h}$ before bedtime to allow the treatment to act throughout the night. In the morning, the residual 5-FU cream was removed with water, and SPF 30 sunscreen was applied.
Assessments included lesion (AK) counts, safety, subject satisfaction, and subject photography using a conventional camera. Evaluations were conducted $48 \mathrm{~h}, 7$ days, and 14 days after treatment, as well as at 1- and 3-month followups.

All subjects provided written informed consent prior to their participation in the study.

\section{RESULTS}

The lesion complete response rate (clinical remission of lesions) 3 months after treatment with DL-PDT and 5-FU was 80\% and 93\%, respectively. The lesion partial response (decrease in lesion severity assessed visually) was $20 \%$ and $7 \%$, respectively. DL-PDT with $16 \%$ MAL cream is approved for a single session, with the possibility of a second session after 3 months, if deemed necessary by the treating physician $[1,8]$. The analysis of the present comparison study is based exclusively on data from a single session of DL-PDT. Considering the close efficacy observed between the two treatments in this study, it is likely that a second session of DL-PDT would yield similar efficacy to 5-FU.

Safety assessment revealed a lower incidence of adverse events (AEs) with DL-PDT (erythema, scales, and scabs) compared with 5-FU (erythema, crusts, pustules, and pruritus). Moreover, the duration of AEs was shorter with DLPDT versus 5-FU, with AEs resolving spontaneously in 5-7 and 27-30 days after treatment, respectively.

In terms of subject satisfaction, all five subjects reported that they preferred DL-PDT because of the lower incidence of AEs and the rapid recovery compared with 5 -FU. In addition, the single-day DL-PDT procedure (application of $16 \%$ MAL and exposure to sunlight) renders this treatment option more convenient compared with the 21-day home application of 5-FU for both the treating physician and patient.

Figures 1 and 2 illustrate two subjects during the course of treatment and follow-up. 

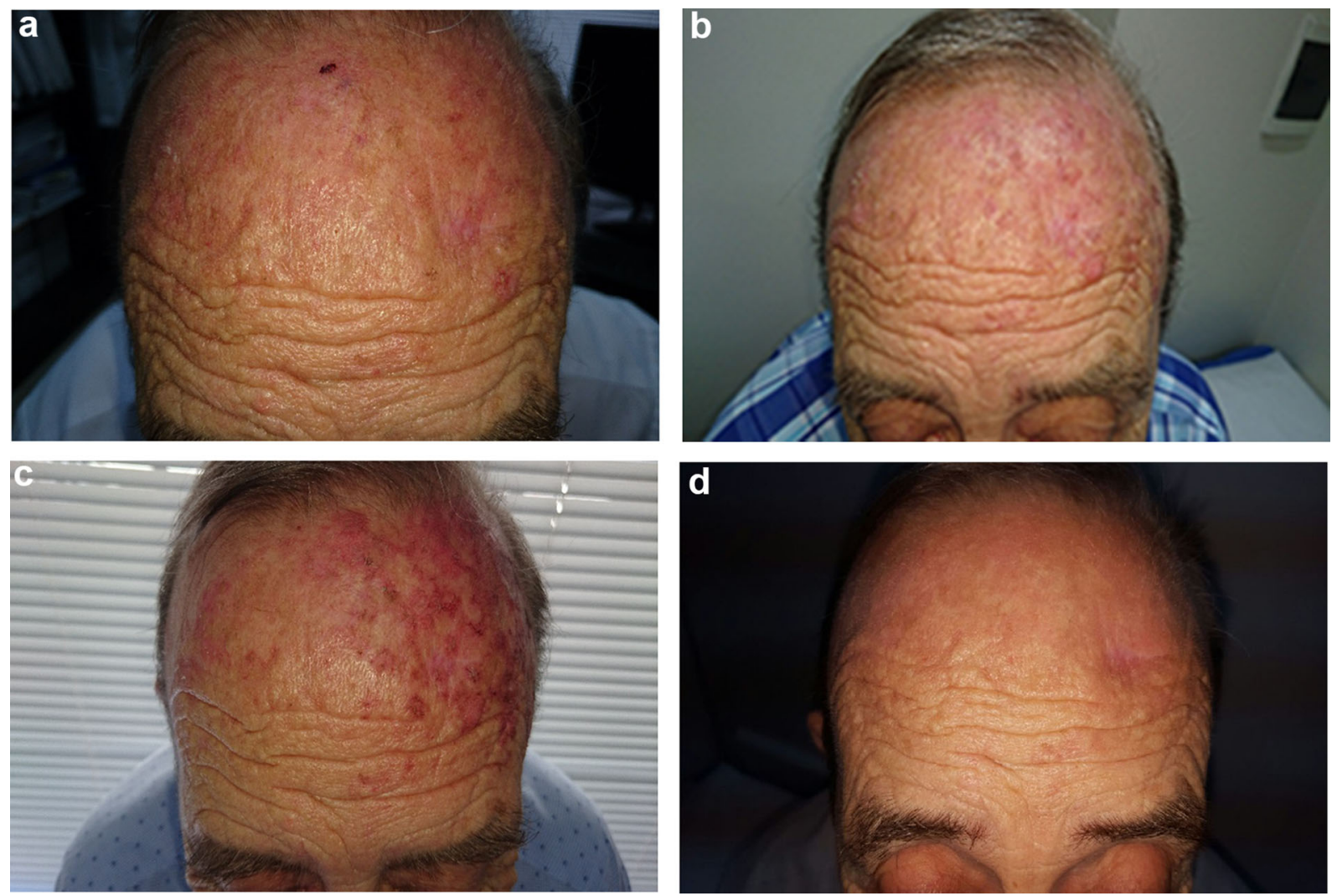

Fig. 1 Subject 1: a before treatment; $\mathbf{b}$ day 7 of 5-FU (right side of image) and day 0 of DL-PDT (left side of image); $\mathbf{c}$ day 14 of 5-FU and day 7 after DL-PDT; $\mathbf{d}$ day 95 after 5-FU and day 88 after DL-PDT
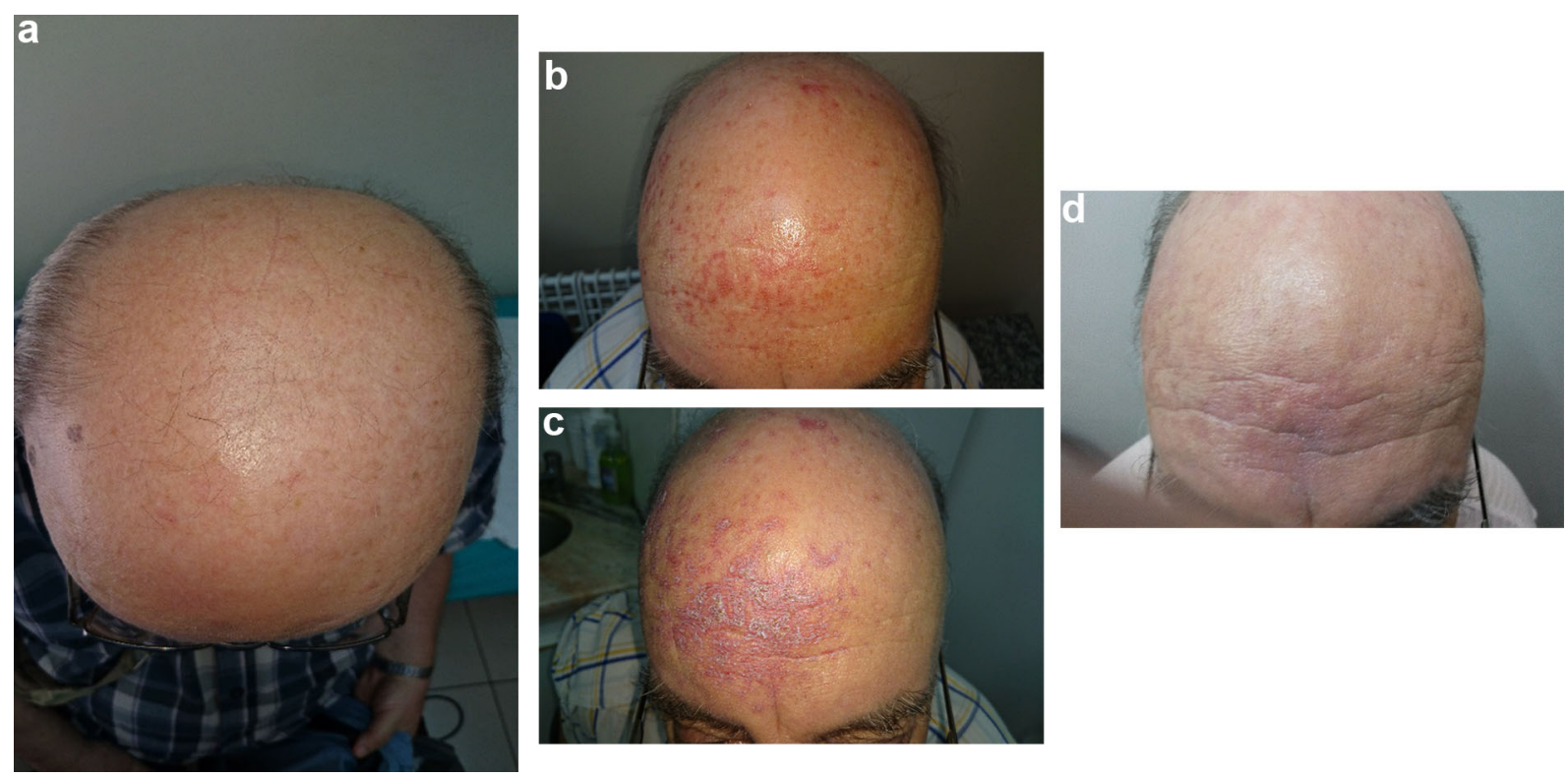

Fig. 2 Subject 2: a before treatment; $\mathbf{b}$ day 7 of 5-FU (left side of image) and day 7 after DL-PDT (right side of image); c day 14 of 5-FU and day 14 after DL-PDT; $\mathbf{d}$ day 30 after 5-FU and day 30 after DL-PDT 


\section{DISCUSSION}

The lesion complete response rate at 3 months was higher for 5-FU compared with DL-PDT. However, although topical 5-FU remains an efficacious option for the treatment of field of cancerization, it is associated with disadvantages that may limit its effectiveness. The patient must adhere to the treatment for 21 days while experiencing treatment-related AEs, which persist until the end of treatment and beyond. The prolonged duration of AEs may impair the social life of patients and consequently affect the effectiveness of the treatment. The advantage of DL-PDT versus 5-FU lies in the lack of systemic AEs.

A limitation of this study is the small number of subjects investigated. Studies with a larger sample size are warranted to confirm these findings.

\section{CONCLUSIONS}

Conclusively, DL-PDT is a favorable therapeutic alternative compared with 5-FU with good efficacy and a better safety profile in terms of incidence and duration of AEs. These advantages allow patients to effectively treat their AK without compromising their social life.

\section{ACKNOWLEDGEMENTS}

Funding. Sponsorship for this study and article processing charges was funded by Galderma. The author had full access to all of the data in this study and takes complete responsibility for the integrity of the data and accuracy of the data analysis.

Authorship. The author meets the International Committee of Medical Journal Editors (ICMJE) criteria for authorship for this manuscript, takes responsibility for the integrity of the work as a whole, and has given final approval to the version to be published.
Medical Writing, Editorial, and Other Assistance. Editorial assistance in the preparation of this manuscript was provided by Sotirios Georgantopoulos, Ph.D., of SG Medical Writing B.V. Support for this assistance was funded by Galderma.

Disclosures. Dr. Gaston Galimberti has served as investigator/advisor for Galderma.

Compliance with Ethics Guidelines. All subjects provided written informed consent prior to their participation in the study.

Data Availability. My manuscript has no associated data or the data will not be deposited.

Open Access. This article is distributed under the terms of the Creative Commons Attribution-NonCommercial 4.0 International License (http://creativecommons.org/licenses/ by-nc/4.0/), which permits any noncommercial use, distribution, and reproduction in any medium, provided you give appropriate credit to the original author(s) and the source, provide a link to the Creative Commons license, and indicate if changes were made.

\section{REFERENCES}

1. Grinblat B, Galimberti G, Chouela E, et al. Daylightmediated photodynamic therapy for actinic damage in Latin America: consensus recommendations. Photodermatol Photoimmunol Photomed. 2016;32:81-7.

2. Rahvar M, Lamel SA, Maibach HI. Randomized, vehicle-controlled trials of topical 5-fluorouracil therapy for actinic keratosis treatment: an overview. Immunotherapy. 2012;4:939-45.

3. Rubel DM, Spelman L, Murrell DF, et al. Daylight photodynamic therapy with methyl aminolevulinate cream as a convenient, similarly effective, nearly painless alternative to conventional photodynamic therapy in actinic keratosis treatment: a randomized controlled trial. Br J Dermatol. 2014;171:1164-71.

4. Lacour JP, Ulrich C, Gilaberte Y, et al. Daylight photodynamic therapy with methyl aminolevulinate cream is effective and nearly painless in treating actinic keratoses: a randomised, investigator-blinded, 
controlled, phase III study throughout Europe. J Eur Acad Dermatol Venereol. 2015;29:2342-8.

5. Wiegell SR, Wulf HC, Szeimies RM, et al. Daylight photodynamic therapy for actinic keratosis: an international consensus: International Society for Photodynamic Therapy in Dermatology. J Eur Acad Dermatol Venereol. 2012;26:673-9.

6. Wiegell SR, Fabricius S, Gniadecka M, et al. Daylight mediated photodynamic therapy of moderate to thick actinic keratoses of the face and scalp: a randomized multicentre study. $\mathrm{Br} \mathrm{J}$ Dermatol. 2012;166:1327-32.
7. Olsen EA, Abernethy L, Kulp-Shorten C, et al. A double-blind, vehicle-controlled study evaluating masoprocol cream in the treatment of actinic keratoses of the head and neck. J Am Acad Dermatol. 1991;24:738-43.

8. See JA, Shumack S, Murrell DF, et al. Consensus recommendations on the use of daylight photodynamic therapy with methyl aminolevulinate cream for actinic keratoses in Australia. Australas J Dermatol. 2016;57:167-74. 